University of Wollongong

Research Online

Faculty of Social Sciences - Papers (Archive) Faculty of Arts, Social Sciences \& Humanities

2014

Mapping the effects of prestimulus EEG band amplitude in an equiprobable Go/NoGo task

Frances M. De Blasio

University of Wollongong, francesd@uow.edu.au

Robert Barry

University of Wollongong, rbarry@uow.edu.au

Follow this and additional works at: https://ro.uow.edu.au/sspapers

Part of the Education Commons, and the Social and Behavioral Sciences Commons

Research Online is the open access institutional repository for the University of Wollongong. For further information contact the UOW Library: research-pubs@uow.edu.au 


\title{
Mapping the effects of prestimulus EEG band amplitude in an equiprobable Go/ NoGo task
}

\author{
Abstract \\ Abstract presented at the 17th World Congress of Psychophysiology (IOP2014) of the International \\ Organization of Psychophysiology (IOP) Hiroshima, Japan, September 23rd to 27th, 2014 \\ Keywords \\ prestimulus, effects, eeg, band, amplitude, equiprobable, mapping, go, task, nogo \\ Disciplines \\ Education | Social and Behavioral Sciences

\section{Publication Details} \\ De Blasio, F. M. \& Barry, R. J. (2014). Mapping the effects of prestimulus EEG band amplitude in an \\ equiprobable Go/NoGo task. International Journal Of Psychophysiology, 94 (2), 148.
}




\section{Mapping the effects of prestimulus EEG band amplitude in an equiprobable Go/NoGo task}

Frances M. De Blasio,

Robert J. Barry

University of Wollongong, Australia

The brain state present at stimulus onset influences the processing outcomes of that stimulus event, and we are interested in mapping these relationships. We have assessed the empirically testable relationships between the electroencephalographic (EEG) amplitude of the four traditional bands (delta, theta, alpha, beta) present immediately prestimulus (- $500 \mathrm{~ms}$ to stimulus onset), and their influence on the event-related potential (ERP) component outcomes in the equiprobable auditory Go/NoGo task. To date we have mapped the influence of two levels (Low/High) of prestimulus $\mathrm{Cz}$ EEG amplitude on five peak-picked ERP components (P1, N1, P2, N2, P3) derived from the lowest and highest accepted trial thirds for Go and NoGo responses. Briefly, prestimulus delta modulated the positivity of each component; prestimulus theta had a stimulus specific effect on the N1, N2, and P3; prestimulus alpha enhanced the positive component amplitudes (P1, P2, P3); and beta modulated the positivity of the early component amplitudes (P1, N1, P2). Using improved methodology, here we assess the nature of the EEG-ERP relationships (i.e., linear and quadratic) in a new sample. Twenty-four participants completed four blocks of an equiprobable auditory Go/NoGo task. Separately for the four traditional bands, the accepted trials were sorted according to the prestimulus EEG amplitude at the site of maximal variability, before they were segmented into deciles and average ERPs were derived. Principal Component Analysis was used to quantify the ERP amplitudes. Six components were assessed: N1-1, Go Processing Negativity (PN), P2, P3, Go Slow Wave (SW), and NoGo Late Positivity (LP). Prestimulus EEG level interacted with component topography producing a complex and differential pattern of linear and quadratic effects across the bands. Prestimulus $\mathrm{Cz}$ delta and Pz theta each modulated the N1-1, P2, P3, SW, and LP components; Pz alpha modulated PN, P3, SW, and LP; and Pz beta amplitude was associated with effects in N1-1, PN, P2, SW, and the LP. Go reaction time was linearly modulated by prestimulus $\mathrm{Cz}$ delta, and $\mathrm{Pz}$ alpha amplitudes. The present results generally confirm, and significantly extend, our prior work in mapping the effects of prestimulus EEG band activity on processing outcomes in this paradigm. These relationships suggest optimal prestimulus brain states for improved processing. 